\title{
The potential contribution of organic salts to new particle growth
}

\author{
K. C. Barsanti ${ }^{1}$, P. H. McMurry ${ }^{2}$, and J. N. Smith ${ }^{1}$ \\ ${ }^{1}$ Atmospheric Chemistry Division, National Center for Atmospheric Research, Boulder, CO, USA \\ ${ }^{2}$ Department of Mechanical Engineering, University of Minnesota, Minneapolis, MN, USA
}

Received: 7 October 2008 - Published in Atmos. Chem. Phys. Discuss.: 11 December 2008

Revised: 28 April 2009 - Accepted: 28 April 2009 - Published: 6 May 2009

\begin{abstract}
Field and lab measurements suggest that lowmolecular weight (MW) organic acids and bases exist in accumulation and nucleation mode particles, despite their relatively high pure-liquid vapor pressures. The mechanism(s) by which such compounds contribute to the mass growth of existing aerosol particles and newly formed particles has not been thoroughly explored. One mechanism by which lowMW compounds may contribute to new particle growth is through the formation of organic salts. In this paper we use thermodynamic modeling to explore the potential for organic salt formation by atmospherically relevant organic acids and bases for two system types: one in which the relative contribution of ammonia vs. amines in forming organic salts was evaluated, the other in which the decrease in volatility of organic acids and bases due to organic salt formation was assessed. The modeling approach employed relied heavily on group contribution and other estimation methods for necessary physical and chemical parameters. The results of this work suggest that amines may be an important contributor to organic salt formation, and that experimental data are greatly needed to improve our understanding of organic salt formation in atmospherically relevant systems and to accurately predict the potential contribution of such salts to new particle growth.
\end{abstract}

\section{Introduction}

The number of aerosol particles acting as cloud condensation nuclei $(\mathrm{CCN})$ is a critical factor in understanding and accurately predicting the feedbacks between aerosols and climate (Novakov and Penner, 1993). It has been suggested that new particle formation (NPF), the formation of stable

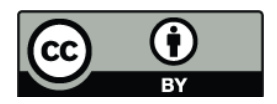

Correspondence to: K. Barsanti (barsanti@ucar.edu) nuclei in the atmosphere and their subsequent growth to particles of a measurable size (typically $>3 \mathrm{~nm}$ ), is an important contributor to CCN (e.g., Kerminen et al., 2005; Laaksonen et al., 2005; Sotiropoulou et al., 2006). Recent modeling work by Spracklen et al. (2008) indicates that NPF in the boundary layer may significantly affect global $\mathrm{CCN}$ concentrations, with predicted increases in the global mean of $3-20 \%$ at $0.2 \%$ water supersaturation and of $5-50 \%$ at $1 \%$ water supersaturation. Such predictions rely on assumptions and approximations of the identities, quantities, and properties of the compounds contributing to particle growth. Those assumptions will have a direct effect on $\mathrm{CCN}$ predictions because of their importance in determining particle hygroscopicity, as well as growth rates and therefore particle size. To illustrate, Spracklen et al. (2008) conclude that more accurate model predictions cannot be achieved without better understanding of growth rates, which in turn will require a better understanding of the compounds contributing to such growth.

Freshly nucleated particles grow by coagulation and predominately, condensation (Weber et al., 1995). Correlations between sulfuric acid $\left(\mathrm{H}_{2} \mathrm{SO}_{4}\right)$ concentrations and particle growth rates indicate that $\mathrm{H}_{2} \mathrm{SO}_{4}$ condensation can explain some, and occasionally all, observed particle growth (Stolzenburg et al., 2005). Growth rates in excess of $\mathrm{H}_{2} \mathrm{SO}_{4}$ condensation suggest that other compounds may be condensing (Weber et al., 1997) or other mechanisms such as reactive uptake may be important (Zhang and Wexler, 2002). In one of the early studies investigating chemical composition of particles formed during NPF events, it was found that event particles were distinguishable from non-event particles by the significant presence of dimethylammonium, possibly present as dimethylammonium sulfate or dimethylammonium bisulfate (Mäkelä et al., 2001). More recent studies employing a Thermal Desorption Chemical Ionization Mass Spectrometer (TDCIMS) support the findings of Mäkelä et al. (2001) and others (e.g., O'Dowd et al., 2002; Zhang et

Published by Copernicus Publications on behalf of the European Geosciences Union. 
al., 2004) that indicate organics contribute to the growth of newly formed particles, and likely include compounds such as low-molecular weight (MW) amines and carboxylic acids (Smith et al., 2008).

In general, based solely on their pure-compound vapor pressures $\left(p_{\mathrm{L}}^{\circ}\right)$, one would not expect low-molecular weight amines and carboxylic acids to contribute to condensational growth of newly formed particles. For example, the $p_{\mathrm{L}}^{\circ}$ value of dimethylamine (C2) at $293 \mathrm{~K}$ is $\sim 2 \times 10^{0}$ atm and acetic acid (C2) is $\sim 2 \times 10^{-2}$ atm, while calculations based on observed growth rates of $1-10 \mathrm{~nm} \mathrm{~h}^{-1}$ (Kulmala et al., 2004) lead to saturation vapor pressures $\left(p_{i}\right)$ of $\sim 4 \times 10^{-16}$ atm for condensing compounds. Even condensation of higher-MW carboxylic acids (e.g., up to C30 diacids) would be negligible at the earliest stages of growth since the Kelvin effect of nanometer-sized nuclei prohibits such compounds from contributing to condensational growth (Zhang and Wexler, 2002). The apparent discrepancy between the $p_{\mathrm{L}}^{\circ}$ values of compounds thought to be contributing to growth of newly formed particles and required $p_{i}$ values suggests that mechanism(s) other than simple condensation of observed organics contribute to new particle growth.

At least two possibilities exist for the contribution of lowMW organic compounds to new particle growth: 1) the formation of accretion products, and 2) the formation of organic salts. Accretion products are higher-MW/low-volatility compounds formed by reactions of organic compounds with each other and/or other atmospheric constituents (e.g., $\mathrm{H}_{2} \mathrm{O}$, $\mathrm{H}_{2} \mathrm{SO}_{4}$ ); reactions can occur in the gas phase, particle phase, and/or heterogeneously (Barsanti and Pankow, 2004). Accretion reactions have been used to explain the apparent discrepancy between measured and calculated contributions of semi-volatile compounds to larger particles (e.g., Jang and Kamens, 2001; Tobias and Ziemann, 2001; Barsanti and Pankow, 2005, 2006). Additionally, Zhang and Wexler (2002) used heterogeneous accretion reactions to explain the contribution of organics to newly formed particles. While the contributions of accretion products are indeed a possibility that is being explored, here we will focus on the potential contribution of organic salts.

It is known that ammonia $\left(\mathrm{NH}_{3}\right)$ neutralizes particles by reacting with $\mathrm{H}_{2} \mathrm{SO}_{4}$ and $\mathrm{HNO}_{3}$ (nitric acid) to form inorganic salts (Jaeschke et al., 1998; Seinfeld and Pandis, 1998), which concurrently shifts the equilibrium of the participating species towards the particle phase (Pankow, 2003; Pinder et al., 2007). Analogously, it has been suggested that in the presence of excess inorganic base, organic acids act to neutralize particles (Mircea et al., 2005; Trebs et al., 2005; Metzger et al., 2006), thereby forming organic salts and shifting the equilibrium of the acids and bases towards the particle phase. Angelino et al. (2001) used laboratory experiments to show that organic salt formation could explain the significant presence of amines in ambient particles. Additionally, the presence of organic salts has been invoked to reconcile modeled and measured hygroscopic growth and $\mathrm{CCN}$ activity of aerosols (Mircea et al., 2005; Metzger and Lelieveld, 2007); which has been supported by recent experimental results of Dinar et al. (2008).

Here we present a thermodynamic consideration of the potential contribution of organic salt formation to the growth of newly formed particles. Equilibrium modeling is applied to two system types: the first addresses the relative importance of amines vs. ammonia in forming organic salts; the second evaluates the decrease in volatility of acids and bases due to the formation of organic salts. The focus of this work is primarily on organic salt formation from low-MW acids and bases, such as dimethylamine (DMA) and acetic acid $(\mathrm{AcOH})$. Organic salt formation involving a higher-MW organic acid, pinic acid, also is considered. The implications of the results are discussed with regard to other atmospherically relevant acids and bases as well. The modeling approach employed relies heavily on group contribution and other estimation methods to obtain necessary physical and chemical parameters, which ultimately highlights the need for experimental studies on organic salts with atmospherically relevant compositions, as such salts may be important contributors to new particle growth.

\section{Methodology}

\subsection{Equilibrium partitioning of atmospherically rele- vant organic acids, bases, and their salts}

The extent to which organic acids and bases exist in nanometer-sized particles depends on their concentrations $\left(c_{i}\right)$; pure-liquid vapor pressures $\left(p_{\mathrm{L}, i}^{\circ}\right)$ or Henry's Law constants $\left(K_{\mathrm{H}, i}\right)$; acid dissociation constants $\left(K_{\mathrm{a}, i}\right)$; and activity coefficients (mole scale, $\zeta_{i}$ ). Additionally, the liquid molarvolume of each constituent $\left(V_{i}\right)$ and the surface tension of the particle mixture $\left(\sigma_{\mathrm{m}}\right)$ will play a role when curvature corrections are considered. When thermodynamic equilibrium is assumed, the following equations can be used, along with mass and charge balance equations, to estimate the amounts of acids, bases, and salts in each phase (where $X_{i}$ is mole fraction):

$$
\begin{aligned}
& p_{i}(\operatorname{atm})=p_{\mathrm{L}, i}^{\circ} \zeta_{i} X_{i} \\
& K_{\mathrm{a}, \text { acid }}=\frac{\zeta_{\mathrm{H}+} X_{\mathrm{H}+} \zeta_{\mathrm{A}-} C_{\mathrm{A}-}}{\zeta_{\mathrm{HA}} X_{\mathrm{HA}}} \\
& K_{\text {a,base }}=\frac{\zeta_{\mathrm{H}+} X_{\mathrm{H}+\zeta_{\mathrm{B}} C_{\mathrm{B}}}}{\zeta_{\mathrm{BH}} X_{\mathrm{BH}}}
\end{aligned}
$$

Including curvature corrections in Eq. (1), based on the Kelvin equation, leads to:

$p_{i}=p_{\mathrm{L}, i}^{\circ} \zeta_{i} X_{i} \exp \left(\frac{V_{i} 2 \sigma_{\mathrm{m}}}{r R T}\right)$ 
where $r$ is particle radius $(\mathrm{cm}), R$ is the ideal gas constant (dyn $\mathrm{cm} \mathrm{mol}^{-1} \mathrm{~K}^{-1}$ ), and $T$ is temperature $(\mathrm{K})$. When considering partitioning to and from a dilute aqueous particle, Henry's law applies and $p_{\mathrm{L}, i}^{\circ}$ in Eqs. (1) and (4) becomes $K_{\mathrm{H}, i}$.

\subsection{Physical and chemical property data sources and es- timation methods}

Limited physical and chemical property data exist for organic acids and bases in systems of the type considered here. Organic salts have been studied widely as ionic liquids: two component organic salts that are liquids at room temperature and contain little or no water. Much data exists on the physical and chemical properties of organic salts in such systems (Zhang et al., 2006; Greaves and Drummond, 2008; and references therein); though it is not entirely clear how applicable such data are for atmospherically relevant systems, which may contain varying amounts of water and multiple organic and inorganic acids and bases. For atmospheric aerosols, equilibrium partitioning is often considered for two phases: 1) a dilute aqueous phase with neutral organic compounds and ionized inorganic compounds, and 2) a mostly organic phase with neutral organic compounds. In this work, assumptions have been made about the composition of nanometer-sized particles, in part to make the best use of available data, estimation methods, and models.

When experimental data were not available for properties of interest, estimation methods were used. For most acids and bases considered, $p_{\mathrm{L}, i}^{\circ}$ values were estimated using the Antoine equation with parameters obtained from NIST Chemistry WebBook (Linstrom and Mallard, 2005; http: //webbook.nist.gov/chemistry/); $K_{\mathrm{H}}$ values also from NIST Chemistry WebBook; and $K_{\mathrm{a}}$ values from Hall (1957; http:// www.webqc.org/pkaconstants.php) and the CRC Handbook of Chemistry and Physics (Lide, 2008). When not available, $p_{\mathrm{L}, i}^{\circ}$ values were estimated using the SIMPOL group contribution method (GCM) of Pankow and Asher (2008). The $K_{\mathrm{a}}$ value for pinic acid was estimated using SPARC (Hilal et al., 1995; http://ibmlc2.chem.uga.edu/sparc/).

As a first approximation, values of $\zeta_{i}$ for neutral species were calculated using UNIFAC (Fredenslund et al., 1977); values of $\zeta_{i}$ for ions were calculated using the Davies equation. The Davies equation is composed of two terms. The first term is based on the Debye-Hückel equation and accounts for long range ion-ion interactions in dilute aqueous ionic solutions $(<\sim 0.01 \mathrm{M})$. The second term is an empirical term and accounts for short range ion-ion interactions and solvation effects in more concentrated aqueous ionic solutions $(<\sim 0.5 \mathrm{M})$. A modified form of the Davies equation is given by Samson et al. (1999):

$\ln =-A z_{i}^{2}\left(\frac{\sqrt{I}}{1+B a_{i} \sqrt{I}}-\frac{C I}{\sqrt{1000}}\right)$ where $\gamma_{i}$ is the molal scale activity coefficient $\left(\zeta_{i}=\gamma_{i} \quad\left(m_{i} \mathrm{MW}_{\mathrm{w}}\right) /\left(X_{i} * 1000\right), \quad m_{i}\right.$ is molality of $\left.i\right)$. The parameters $A$ and $B$ are dependent on the dielectric constant, density, and temperature of the solvent, in the case of the Davies equation, water at $298 \mathrm{~K}$ and $1 \mathrm{~atm}\left(A=1.1744 \mathrm{~kg}^{1 / 2} \mathrm{~mol}^{-1 / 2}\right.$, $\left.B=3.285 \times 10^{9} \mathrm{~kg}^{1 / 2} \mathrm{~mol}^{-1 / 2} \mathrm{~m}^{-1}\right) ; \quad I \quad$ is ionic strength $\left(=\Sigma_{i} m_{i} z_{i}^{2}, z\right.$ is the charge on ion $\left.i\right)$; and $a_{i}$ is the effective diameter of $i\left(=3 \times 10^{-10} \mathrm{~m}\right)$. In the standard Davies equation, the empirical term takes the form $b I$, where $b=0.2$ to 0.3; in the modified Davies equation of Samson et al. (1999), $C=0.2$. The reference state for the ionic species is infinite dilution, defined for the mean ionic activity coefficient such that as $m_{+} m_{-} \rightarrow 0, \gamma_{+} \gamma_{-} \rightarrow 1$. The reference state for the neutral species, including water, is the pure liquid; as $X_{i} \rightarrow 1$, $\zeta_{i} \rightarrow 1$.

It was assumed here that partial molar volumes were equivalent to pure-compound molar volumes $\left(V_{i}\right)$, and were estimated using ACD/ChemSketch (2006). Values of $\sigma_{i}$ also were estimated using ACD/ChemSketch (2006). Values of $\sigma_{\mathrm{m}}$ were calculated using the method of Sprow and Prausnitz (1966) as described in Poling et al. (2001); using the method of Tyn and Calus (1975) to determine molar volume at boiling temperature and the method of Suarez et al. (1989) to calculate the surface area of each component, also as described in Poling et al. (2001). The second-order GCM of Constantinou and Gani (1994) was used to estimate the critical volume $\left(V_{\mathrm{c}}\right)$ of pinic acid. For all other compounds $V_{\mathrm{c}}$ values were obtained from the CRC Handbook of Chemistry and Physics (Lide, 2008). The values of $\sigma_{\mathrm{m}}$ were calculated based on the initial compositions of the particles, and thus do not take into account the presence of ions. Implications of this approximation are discussed further in Sect. 3.2. While models are available that take into account the presence of inorganic and organic ions ( $\mathrm{Li}$ and $\mathrm{Lu}, 2001$; Raatikainen et al., 2008), such models require parameters fit to experimental data, which are unavailable for systems of the type considered here. Physical and chemical property data for all compounds considered are summarized in Table 1.

\subsection{Initial particle composition and system types}

In this work we evaluated the potential for organic salt formation in the atmosphere by considering equilibrium partitioning of acids and bases between the gas and particle phases for two system types, differentiated by the assumed initial composition of nanometer-sized particles. The first system type (ST 1) was designed to investigate the relative importance of amines vs. $\mathrm{NH}_{3}$ in forming organic salts by considering partitioning of gas-phase amines, $\mathrm{NH}_{3}$, and an organic acid to a dilute aqueous particle. Concentrations of amines were based on ambient measurements in southern Sweden (Grönberg et al., 1992). Similar levels have been reported, on the order of tens or less of ppt, for ambient measurements at other locations (e.g., Akyüz, 2007), while much higher levels also 
Table 1. Chemical and physical property parameters for acids and bases considered.

\begin{tabular}{lcccccc}
\hline & $p_{\mathrm{L}}^{\mathrm{o}}(\mathrm{atm})^{\mathrm{a}}$ & $K_{\mathrm{H}}^{\mathrm{a}}\left(\mathrm{M} \mathrm{atm}^{-1}\right)$ & $\mathrm{p} K_{\mathrm{a}}\left(=-\log K_{\mathrm{a}}\right)$ & $V_{i}^{\mathrm{f}}\left(\mathrm{cm}^{3} \mathrm{~mol}^{-1}\right)$ & $\left.\sigma_{i}^{\mathrm{f}}(\mathrm{dyn} \mathrm{cm})^{-1}\right)$ & $V_{\mathrm{c}}^{\mathrm{c}}\left(\mathrm{cm}^{3} \mathrm{~mol}^{-1}\right)$ \\
\hline ammonia $\left(\mathrm{NH}_{3}\right)$ & $9.81 \times 10^{0}$ & $6.2 \times 10^{1}$ & $9.25^{\mathrm{c}}$ & $\mathrm{n} / \mathrm{a}$ & $\mathrm{n} / \mathrm{a}$ & $\mathrm{n} / \mathrm{a}$ \\
dimethylamine (DMA) & $2.04 \times 10^{0}$ & $3.1 \times 10^{1}$ & $10.73^{\mathrm{d}}$ & 70.3 & 15.50 & 182.5 \\
acetic acid (AcOH) & $2.09 \times 10^{-2}$ & $8.8 \times 10^{3}$ & $4.76^{\mathrm{c}}$ & 56.1 & 31.90 & 171.0 \\
pinic acid & $7.69 \times 10^{-10 \mathrm{~b}}$ & $\mathrm{n} / \mathrm{a}$ & $4.62^{\mathrm{e}}$ & 153.8 & 44.50 & $520.8^{\mathrm{g}}$ \\
water & $3.09 \times 10^{-2}$ & $\mathrm{n} / \mathrm{a}$ & $14.00^{\mathrm{c}}$ & 18.0 & 72.01 & 56.0 \\
\hline
\end{tabular}

a Linstrom and Mallard (2005, http://webbook.nist.gov/chemistry/)

b Pankow and Asher (2008)

c CRC Handbook of Chemistry and Physics (Lide, 2008)

${ }^{\mathrm{d}}$ Hall (1957, http://www.webqc.org/pkaconstants.php)

e SPARC (Hilal et al., 1995; http://ibmlc2.chem.uga.edu/sparc/)

${ }^{\mathrm{f}}$ ACD/ChemSketch (2006)

g Constantinou and Gani (1994)

Table 2. Relative amounts of dimethylamine (DMA) and ammonia $\left(\mathrm{NH}_{3}\right)$ predicted in the particle phase, expressed as fractions of total base predicted in the particle phase, as a function of gas-phase DMA and $\mathrm{NH}_{3}$ levels (gas-phase acetic acid=100 ppt). Total fractions of DMA and $\mathrm{NH}_{3}$ are emboldened. Activity and curvature corrections have been neglected.

\begin{tabular}{lccc}
\hline$f_{i}=n_{i, \mathrm{p}} / n_{\text {totalbase } \mathrm{p}}$ & $\mathrm{NH}_{3, \mathrm{~g}}=1000 \mathrm{ppt} ; \mathrm{DMA}_{\mathrm{g}}=1 \mathrm{ppt}$ & $\mathrm{NH}_{3, \mathrm{~g}}=100 \mathrm{ppt} ; \mathrm{DMA}_{\mathrm{g}}=1 \mathrm{ppt}$ & $\mathrm{NH}_{3, \mathrm{~g}}=100 \mathrm{ppt} ; \mathrm{DMA} \mathrm{g}=10 \mathrm{ppt}$ \\
\hline$f_{\text {DMAH }}+$ & 0.015 & 0.133 & 0.605 \\
$f_{\text {DMAp }}$ & $\ll 0.001$ & $\ll 0.001$ & $\ll 0.001$ \\
$f_{\text {DMAH }}+f_{\text {DMAp }}$ & $\mathbf{0 . 0 1 5}$ & $\mathbf{0 . 1 3 3}$ & $\mathbf{0 . 6 0 5}$ \\
$f_{\mathrm{NH}_{4}^{+}}$ & 0.983 & 0.866 & 0.394 \\
$f_{\mathrm{NH}_{3}}$ & 0.002 & 0.001 & $\ll 0.001$ \\
$f_{\mathrm{NH}_{4}^{+}}+f_{\mathrm{NH}_{3 \mathrm{p}}}$ & $\mathbf{0 . 9 8 5}$ & $\mathbf{0 . 8 6 7}$ & $\mathbf{0 . 3 9 4}$ \\
\hline
\end{tabular}

have been reported, on the order of tens to hundreds of $\mathrm{ppb}$ (Rabaud et al., 2003; Rampfl et al., 2008).

The second system type (ST 2) was designed to investigate the contribution of organic salt formation to the reduction in volatility of organic acids and bases from nanometersized particles. In this system type, gas/particle partitioning of acids and bases was considered for aqueous particles with initial organic acid and base mole fractions of $X_{\text {acid, initial }}=0.25$ and $X_{\text {base, } \text { initial }}=0.25$. Since the focus of this work is on low-MW organic acids and bases, $\mathrm{AcOH}$ and DMA were chosen as representative atmospheric organic compounds for both system types. For ST 1, organic salt formation involving other low-MW aliphatic amines also was considered. For ST 2, organic salt formation involving a higher-MW organic acid, pinic acid, also was considered. For both system types, implications of the results for other atmospherically relevant organic acids/bases are discussed.

\section{Results}

\subsection{Salts of acetic acid, amines, and ammonia in dilute aqueous particles, neglecting activity and curvature corrections (ST 1)}

For an aqueous nanometer-sized particle, the relative amounts of particle-phase DMA and $\mathrm{NH}_{3}$ predicted at equilibrium are shown in Table 2. Activity and curvature corrections have been neglected for this dilute system. Regarding the latter, reported surface tension measurements indicate that $\sigma_{\mathrm{m}}$ of dilute aqueous DMA solutions (Hyvärinen et al., 2004) are less than $\sigma_{\mathrm{m}}$ of dilute aqueous $\mathrm{NH}_{3}$ solutions (Paul and Chandra, 2005). Therefore, while the absolute amount of organic salts formed likely will change as a function of surface tension (and therefore particle size), the relative importance of amines vs. $\mathrm{NH}_{3}$ may not change. The results presented in Table 2 are for assumed steady-state, gas-phase levels of $100 \mathrm{ppt} \mathrm{AcOH}, 1-10 \mathrm{ppt}$ DMA, and 100-1000 ppt $\mathrm{NH}_{3}$. The results suggest that when the level of gas-phase DMA (DMA $)$ is within an order of magnitude (or greater) of gas-phase $\mathrm{NH}_{3}\left(\mathrm{NH}_{3, \mathrm{~g}}\right)$, DMA $\left(\mathrm{DMA}_{\mathrm{p}}+\mathrm{DMAH}^{+}\right.$, where $\mathrm{DMA}_{\mathrm{p}} \ll \mathrm{DMAH}^{+}$) will be more abundant in the particle 
Table 3. Observed low and high levels of aliphatic amines measured by Grönberg et al. (1992), and their Henry's Law ( $\left.K_{\mathrm{H}}\right)$ and acid dissociation $\left(K_{\mathrm{a}}\right.$, as $\left.\mathrm{p} K_{\mathrm{a}}\right)$ constants.

\begin{tabular}{lcccc}
\hline Amine & Low $(\mathrm{ppt})$ & High $(\mathrm{ppt})$ & $K_{\mathrm{H}}\left(\mathrm{M} \mathrm{atm}^{-1}\right)^{\mathrm{a}}$ & $\mathrm{p} K_{\mathrm{a}}\left(=-\log K_{\mathrm{a}}\right)^{\mathrm{b}}$ \\
\hline methylamine & 2.4 & 29.4 & 36 & 10.62 \\
dimethylamine & 0.6 & 7.6 & 31 & 10.64 \\
trimethylamine & 1.5 & 39.1 & 9.6 & 9.76 \\
diethylamine & 0.4 & 11.5 & 39 & 10.98 \\
triethylamine & trace & trace & 29 & 9.25 \\
total amines & 4.9 & 87.6 & $\mathrm{n} / \mathrm{a}$ & $\mathrm{n} / \mathrm{a}$ \\
\hline
\end{tabular}

Additional compounds included in system type one (ST 1) particles: ammonia $\left(\mathrm{NH}_{3}\right), 10^{2}-10^{4} \mathrm{ppt}\left(\mathrm{Seinfeld}\right.$ and Pandis, 1998), $K_{\mathrm{H}}=61^{\mathrm{a}}$, $\mathrm{p} K_{\mathrm{a}}=9.25^{\mathrm{c}}$; and acetic acid $(\mathrm{AcOH}), 10^{2}-10^{3}$ ppt (Glasius et al., 2001; de Gouw et al., 2003), $K_{\mathrm{H}}=8800^{\mathrm{a}}, \mathrm{p} K_{\mathrm{a}}=4.76^{\mathrm{c}}$

${ }^{a}$ Linstrom and Mallard (2005; http://webbook.nist.gov/chemistry/)

${ }^{\mathrm{b}}$ Hall (1957, http://www.webqc.org/pkaconstants.php)

c CRC Handbook of Chemistry and Physics (Lide, 2008)

phase than $\mathrm{NH}_{3}\left(\mathrm{NH}_{3, \mathrm{p}}+\mathrm{NH}_{4}^{+}\right.$, where $\left.\mathrm{NH}_{3, \mathrm{p}} \ll \mathrm{NH}_{4}^{+}\right)$. This is due to DMA and $\mathrm{NH}_{3}$ having Henry's Law constants of similar magnitude, 31 and $62 \mathrm{M} \mathrm{atm}^{-1}$ respectively; but DMA having significantly greater basicity than $\mathrm{NH}_{3}$, with $\Delta \mathrm{p} K_{\mathrm{a}}\left(\mathrm{p} K_{\mathrm{a}, \text { base }}-\mathrm{p} K_{\mathrm{a} \text {,acid }}\right)=5.88$ for DMA and $\mathrm{AcOH}$ and $\Delta \mathrm{p} K_{\mathrm{a}}=4.49$ for $\mathrm{NH}_{3}$ and $\mathrm{AcOH}$. It should be noted that the predicted amounts of DMA in the particle phase are greater than what would be predicted for equilibration of DMA alone (i.e., based on $K_{\mathrm{H}}$ value only, with no acid and therefore no organic salt formation). Thus when considering the potential for other atmospherically relevant amines to form organic salts, in addition to their concentrations and $K_{\mathrm{H}}$ values, $\mathrm{p} K_{\mathrm{a}}$ (or $\Delta \mathrm{p} K_{\mathrm{a}}$ ) values must be considered.

Table 3 lists the low and high levels of five aliphatic amines measured by Grönberg et al. (1992), and their $K_{\mathrm{H}}$ and $\mathrm{p} K_{\mathrm{a}}$ values. Those values, along with gas-phase amine levels reported by Rampfl et al. (2008), were used here to represent a range of possible values for ambient amines. For these general considerations, the fraction of amines in the particle phase ( $f_{\text {amines }}=n_{\text {amines, } \mathrm{p}} / n_{\text {totalbase, } \mathrm{p}}$, where $n$ is mols) is shown in Fig. 1, as a function of gas-phase $\mathrm{NH}_{3}$ and amine levels, and $K_{\mathrm{H}}$ and $\Delta \mathrm{p} K_{\mathrm{a}}$ values $\left(\mathrm{p} K_{\mathrm{a}, \text { amine }}-\mathrm{p} K_{\mathrm{a}, \mathrm{AcOH}}\right)$. From Fig. 1 it can be seen that when the level of gas-phase amines is on the order of gas-phase $\mathrm{NH}_{3}, K_{\mathrm{H}}$ and $\Delta \mathrm{p} K_{\mathrm{a}}$ values play a significant role in determining the amount of amines vs. the amount of $\mathrm{NH}_{3}$ in the particle phase. While DMA was predicted to be more abundant than $\mathrm{NH}_{3}$ in the particle phase when the levels of $\mathrm{DMA}_{\mathrm{g}}$ were within an order of magnitude of $\mathrm{NH}_{3, \mathrm{~g}}$, amines with $K_{\mathrm{H}}=10$ and $\Delta \mathrm{p} K_{\mathrm{a}}=5.00$ are predicted to be less abundant in the particle phase even with equivalent levels of amines and $\mathrm{NH}_{3}$ in the gas phase. For these particular $K_{\mathrm{H}}$ and $\Delta \mathrm{p} K_{\mathrm{a}}$ values, at the 10:1, 1:1 and 1:10 gas-phase ratios, increasing $\Delta \mathrm{p} K_{\mathrm{a}}$ is predicted to play a greater role than increasing $K_{\mathrm{H}}$ in promoting organic salt formation; while at the 100:1 gas-phase ratio, increasing

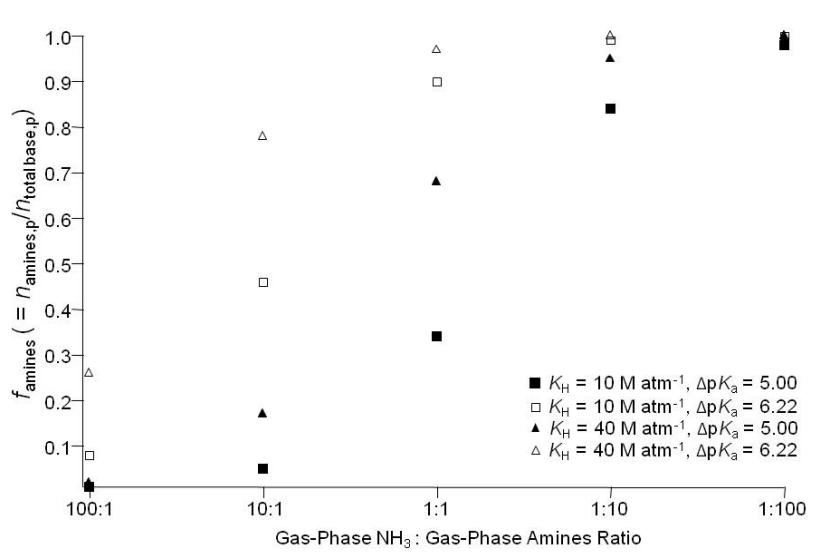

Fig. 1. Fraction of amines predicted in the particle phase, $f_{\text {amines }}$ $\left(=n_{\text {amines, } \mathrm{p}} / n_{\text {totalbase, }}\right)$, for system type one (ST 1$)$ particles (dilute aqueous) as a function of gas-phase $\mathrm{NH}_{3}$ and amine levels, and $K_{\mathrm{H}}$ and $\Delta \mathrm{p} K_{\mathrm{a}}\left(\mathrm{p} K_{\mathrm{a}, \text { amine }}-\mathrm{p} K_{\mathrm{a}, \mathrm{AcOH}}\right)$ values.

$K_{\mathrm{H}}$ is predicted to play a greater role. Also from Fig. 1 it can be seen that when amines greatly exceed $\mathrm{NH}_{3}$ in the gas phase (or when $\mathrm{NH}_{3}$ greatly exceeds DMA), $K_{\mathrm{H}}$ and $\Delta \mathrm{p} K_{\mathrm{a}}$ values become less important in predicting the relative contribution of amines vs. $\mathrm{NH}_{3}$ to organic salt formation. In such cases, $c_{i}$ becomes the dominant driving force for organic salt formation.

\subsection{Volatility of organic acids and dimethylamine in aqueous particles containing organic salts, includ- ing activity and curvature corrections (ST 2)}

Figure 2 illustrates the predicted equilibrium mass fractions of DMA in the gas phase $\left(\mathrm{DMA}_{\mathrm{g}}\right)$ and particle phase $\left(\mathrm{DMA}_{\mathrm{p}}+\mathrm{DMAH}^{+}\right)$; and the sensitivity of organic salt predictions to $p_{\mathrm{L}}^{\circ}$ and $\Delta \mathrm{p} K_{\mathrm{a}}$ values (organic salt formation w/AcOH, ST $2_{\mathrm{AcOH}}$, vs. w/pinic acid, ST 2 pinic), to $\sigma_{\mathrm{m}}$ 


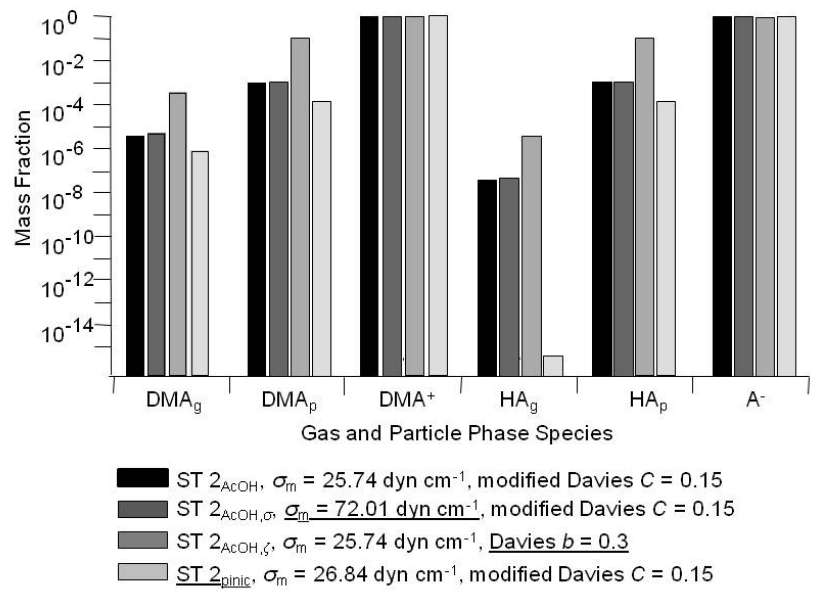

Fig. 2. The predicted equilibrium distribution of dimethylamine, acetic acid, and pinic acid between the gas $\left(\mathrm{DMA}_{\mathrm{g}}, \mathrm{HA}_{\mathrm{g}}\right)$ and particle $\left(\mathrm{DMA}_{\mathrm{p}}, \mathrm{DMAH}^{+}, \mathrm{HA}_{\mathrm{p}}, \mathrm{A}^{-}\right)$phases for system type two (ST 2) particles (aqueous particles $w / X_{\mathrm{HA}}$, initial $=X_{\mathrm{DMA} \text {, initial }}=0.25$ ), shown as mass fraction in each phase. The relative mass fractions illustrate the sensitivity of predictions to surface tension estimation (ST $2 \mathrm{AcOH}, \sigma$ ), activity coefficient estimation (ST $\left.2 \mathrm{AcOH}_{,}\right)$, and vapor pressures/acid dissociation constants (ST 2 pinic).

estimation (ST $2 \mathrm{AcOH}, \sigma$ ), and to $\zeta$ estimation (ST $2 \mathrm{AcOH}, \zeta_{\zeta}$ ). Most of the DMA mass is predicted to be in the particle phase as $\mathrm{DMAH}^{+}$, with $\mathrm{DMAH}_{\text {pinic }}^{+}>\mathrm{DMAH}_{\mathrm{AcOH}}^{+}>$ $\mathrm{DMAH}_{\mathrm{AcOH}, \sigma}^{+}>\mathrm{DMAH}_{\mathrm{AcOH}, \zeta}^{+}$(see DMA, Fig. 2). The same is true for the acids, AcOH (ionic form) in ST $2 \mathrm{AcOH}$ and pinic acid (ionic form) in ST 2 pinic (see $\mathrm{HA}_{\mathrm{g}}$, Fig. 2). Regarding sensitivity to $p_{\mathrm{L}}^{\circ}$ and $\Delta \mathrm{p} K_{\mathrm{a}}$ values, ST 2 pinic

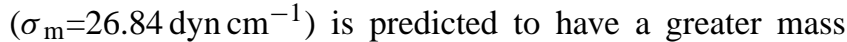
fraction of $\mathrm{DMAH}^{+}$than ST $2 \mathrm{AcOH}\left(\sigma_{\mathrm{m}}=25.74 \mathrm{dyn} \mathrm{cm}^{-1}\right)$. While the estimated surface tension is slightly greater in the system with pinic acid and $\zeta_{\text {pinic }}>\zeta_{\text {acetic }}$, it is the much lower $p_{\mathrm{L}}^{\circ}$ of pinic acid than that of acetic acid, and the greater $\Delta \mathrm{p} K_{\mathrm{a}}$ for the organic salt of pinic acid $\left(\mathrm{p} K_{\mathrm{a}, \mathrm{DMA}}-\mathrm{p} K_{\mathrm{a}, \mathrm{pinic}}=6.00\right)$ than that of acetic acid, that contribute to the greater extent of organic salt formation.

Regarding sensitivity to surface tension, for ST $2 \mathrm{AcOH}$ (initial composition: $X_{\text {water }}=0.5, X_{\text {acid }}=X_{\text {base }}=0.25$ ), $\sigma_{\mathrm{m}}$ is calculated as described in Sect. 2.2. That calculated value is similar to $\sigma_{\mathrm{m}}$ for a non-aqueous organic mixture when calculated using a simple binary approach, $\sigma_{\mathrm{m}}=X_{\text {acid }} \sigma_{\text {acid }}+X_{\text {base }} \sigma_{\text {base }}$. Experimental data have shown that measured $\sigma_{\mathrm{m}}$ values for ionic liquids are typically greater than that for non-ionic organic liquids but less than that for pure water (Greaves et al., 2006). For dilute aqueous organic salt solutions, the presence of amines and $\mathrm{NH}_{3}$ tends to lower surface tension (Mmereki et al., 2000; Donaldson, 1990), while the presence of an inorganic acid and subsequent salt formation increases surface tension (Weissenborn, 1996). Raatikainen et al. (2008) found that for organic salt solutions with amines and inorganic acids, $\sigma_{\text {acid }}>\sigma_{\mathrm{m}} \gg \sigma_{\text {base }}$. Therefore, in ST $2 \mathrm{AcOH}, \sigma \sigma_{\mathrm{m}}$ was set $=\sigma_{\mathrm{w}}$ as an approximate upper limit for the surface tension of the organic salt solutions considered here. While the increased surface tension of the mixture does result in a predicted increase in $\mathrm{DMA}_{\mathrm{g}}$ and thus a decrease in predicted particlephase DMA and $\mathrm{AcOH}$, this effect is small compared to the predicted effects of activity $\left(=X_{i} \zeta_{i}\right)$, discussed below.

Regarding sensitivity to activity coefficients, the standard and modified Davies equations are typically valid for solutions with ionic strengths $<0.5 \mathrm{M}$. Samson et al. (1999) found that for more concentrated ionic solutions (0.5 to $1.5 \mathrm{M}$ ) better agreement with experimental data was achieved by reducing the parameter $C$ in Eq. (5) from 0.2 to 0.15 . While the ionic strengths of the solutions considered here are significantly greater than $1.5 \mathrm{M}$, models that are valid at higher ionic strengths require parameters fit to experimental data, which are unavailable for systems of the type considered here. For ST $2 \mathrm{AcOH}$, $\zeta_{\text {ions }}$ were calculated using the modified Davies equation with $C=0.15$. The standard Davies equation with $b=0.2$ and $b=0.3$ also was used to calculate $\zeta_{\text {ions. }}$ The range in calculated $\zeta_{\text {ions values is }}$ significant, $\sim 10^{0}$ to $10^{2}$, and therefore estimation of $\zeta$ ions has the greatest affect on the predicted extent of organic salt formation. As the calculated $\zeta$ ions values increase, the predicted amounts of $\mathrm{DMAH}^{+}$decrease, increasing $\mathrm{DMA}_{\mathrm{p}}$ and DMA $_{\mathrm{g}}$. However, even when $\zeta_{\text {ions }} \approx 10^{2}(b=0.3)$, the mass fraction of $\mathrm{DMAH}^{+} \approx 0.9\left(\mathrm{ST} 22_{\mathrm{AcOH}, \zeta}\right)$.

\section{Discussion and conclusions}

While amines have been detected in ambient accumulation mode (Silva and Prather, 2000; Denkenberger et al., 2007; Moffet et al., 2008) and nucleation mode (Mäkelä et al., 2001; Smith et al., 2008) particles, the mechanism(s) by which amines contribute to such particles has not been fully explored. As noted previously, the $p_{\mathrm{L}}^{\circ}$ values of low-MW amines found in the atmosphere are too high for such compounds to contribute to condensational growth of particles. This would be true to an even greater extent for the growth of newly formed particles, due to the Kelvin effect. Chamber studies have shown that oxidation of low-MW amines results in the formation of secondary organic aerosols (Pitts et al., 1978; Angelino et al., 2001; Murphy et al., 2007). Particle formation in the experiments of Angelino et al. (2001) and Murphy et al. (2007) was attributed to condensation of amine oxidation products, as well as the formation of aminium salts (w/nitric and/or sulfuric acids). Murphy et al. (2007) found that for aminium nitrate salts, amines generally partitioned back to the gas-phase as gas-phase amines were reacted away, leaving ammonium nitrate in the particle-phase; while for an aminium sulfate salt, methylamine appeared to displace ammonia, resulting in almost complete conversion to methylaminium sulfate. 
In this work, the greater $\Delta \mathrm{p} K_{\mathrm{a}}$ values of the aminium salts over the ammonium salts in ST 1 particles influenced the predicted extent to which each of the bases formed organic salts. When levels of $\mathrm{DMA}_{\mathrm{g}}$ and $\mathrm{NH}_{3, \mathrm{~g}}$ were of the same order of magnitude, the formation of the dimethylaminium salt was predicted to be greater than the formation of the ammonium salt. In a more general consideration of the formation of aminium salts, when gas-phase amines and $\mathrm{NH}_{3}$ levels were of the same order of magnitude, $K_{\mathrm{H}}$ values of the amines and $\Delta \mathrm{p} K_{\mathrm{a}}$ values of the organic salts significantly influenced the predicted extent of organic salt formation, with $\Delta \mathrm{p} K_{\mathrm{a}}$ values having the greatest influence in the systems considered. In aqueous systems, a greater $\Delta \mathrm{p} K_{\mathrm{a}}$ value indicates a greater degree of ionization, which would shift the equilibrium of the acids and bases to the particle phase. Even in non-aqueous systems $\Delta \mathrm{p} K_{\mathrm{a}}$ values may give some insight into the degree of ionization. Yoshizawa et al. (2003) and Belieres and Angell (2007) showed that $\Delta \mathrm{p} K_{\mathrm{a}}$ values of ionic liquids were approximately linearly correlated with excess boiling points. Yoshizawa et al. (2003) also found that ionic liquids with $\Delta \mathrm{p} K_{\mathrm{a}}$ values $>10$ exhibited properties indicating essentially complete proton transfer.

In dilute aqueous systems, ionic species have $\zeta_{i}<1$, favoring the formation of organic salts as described above. In ST 2 particles, estimated $\zeta_{i}$ values for organic ions ranged from $10^{0}$ to $10^{2}$, as a function of the chosen empirical parameter in the Davies equation. Estimated $\zeta_{i}$ values for neutral organic acids and bases were $\approx 1$ (with the exception of pinic acid, $\zeta_{\text {pinic }} \approx 10^{1}$ ). In particles containing DMA and $\mathrm{AcOH}$, varying $\zeta_{\text {ions }}$ was predicted to have a greater effect on aminium salt formation than varying $\sigma_{\mathrm{m}}$. The extent of organic salt formation in the systems considered here appears to be most sensitive to $\Delta \mathrm{p} K_{\mathrm{a}}$ and $\zeta_{i}$ values. However $c_{i}, K_{\mathrm{H}, \mathrm{i},} p_{\mathrm{L}, i}^{\circ}$, and $\sigma_{\mathrm{m}}$ values clearly play a role. Due to the lack of equilibrium data for the types of organic salt solutions considered here, and the limited modeling capabilities for highly concentrated solutions of neutral and ionized organics, the results are intended to provide an indication of the sensitivity of organic salt formation to various parameters considered and the overall potential for organic salt formation, rather than the absolute extent of organic salt formation for atmospherically relevant systems. Experimental data will greatly improve our understanding of organic salt formation in atmospherically relevant systems, and our ability to accurately predict the extent to which such salts contribute to the mass growth of existing aerosols and newly formed particles.

Acknowledgements. The authors would like to acknowledge the helpful comments of J. Pankow. This research was supported by the Office of Science (BER), US Department of Energy, Grant No. DE-FG-02-05ER63997. The National Center for Atmospheric Research is operated by the University Corporation for Atmospheric Research under the sponsorship of the National Science Foundation.

Edited by: J. G. Murphy

\section{References}

ACD/ChemSketch Freeware: Version 10.00, Advanced Chemistry Development, Inc., Toronto, ON, Canada, www.acdlabs.com, last access: September, 2008, 2006.

Akyüz, M.: Simultaneous determination of aliphatic and aromatic amines in indoor and outdoor air samples by gas chromatography-mass spectrometry, Talanta, 71, 486-492, 2007.

Angelino, S., Suess, D. T., and Prather, K. A.: Formation of aerosol particles from reactions of secondary and tertiary alkylamines: Characterization by aerosol time-of-flight mass spectrometry, Environ. Sci. Technol., 35, 3130-3138, 2001.

Barsanti, K. C. and Pankow, J. F.: Thermodynamics of the formation of atmospheric organic particulate matter by accretion reactions - part 1: Aldehydes and ketones, Atmos. Environ., 38, 4371-4382, 2004

Barsanti, K. C. and Pankow, J. F.: Thermodynamics of the formation of atmospheric organic particulate matter by accretion reactions - part 2. Dialdehydes, methylglyoxal, and diketones, Atmos. Environ., 39, 6597-6607, 2005.

Barsanti, K. C., and Pankow, J. F.: Thermodynamics of the formation of atmospheric organic particulate matter by accretion reactions - part 3: Carboxylic and dicarboxylic acids, Atmos. Environ., 40, 6676-6686, 2006.

Belieres, J. P. and Angell, C. A.: Protic ionic liquids: Preparation, characterization, and proton free energy level representation, J. Phys. Chem. B, 111, 4926-4937, 2007.

Constantinou, L. and Gani, R.: New group-contribution method for estimating properties of pure compounds, Aiche J., 40, 1697 1710, 1994.

de Gouw, J. A., Goldan, P. D., Warneke, C., Kuster, W. C., Roberts, J. M., Marchewka, M., Bertman, S. B., Pszenny, A. A. P., and Keene, W. C.: Validation of proton transfer reaction-mass spectrometry (PTR-MS) measurements of gas-phase organic compounds in the atmosphere during the New England Air Quality Study (NEAQS) in 2002, J. Geophys. Res.-Atmos, 108, 4682 doi:10.1029/2003jd003863, 2003.

Denkenberger, K. A., Moffet, R. C., Holecek, J. C., Rebotier, T. P., and Prather, K. A.: Real-time, single-particle measurements of oligomers in aged ambient aerosol particles, Environ. Sci. Technol., 41, 5439-5446, 2007.

Dinar, E., Anttila, T., and Rudich, Y.: CCN activity and hygroscopic growth of organic aerosols following reactive uptake of ammonia, Environ. Sci. Technol., 42, 793-799, 2008.

Donaldson, D. J.: Adsorption of atmospheric gases at the air-water interface. I. $\mathrm{NH}_{3}$, J. Phys. Chem. A, 103, 62-70, 1990.

Fredenslund, A., Gmehling, J., Michelsen, M. L., Rasmussen, P., and Prausnitz, J. M.: Computerized design of multicomponent distillation-columns using UNIFAC group contribution method for calculation of activity-coefficients, Ind. Eng. Chem. Proc. DD, 16, 450-462, 1977.

Glasius, M., Boel, C., Bruun, N., Easa, L. M., Hornung, P., Klausen, H. S., Klitgaard, K. C., Lindeskov, C., Møller, C. K., Nissen, H., Petersen, A. P. F., Kleefeld, S., Boaretto, E., Hansen, T. S., Heinemeier, J., and Lohse, C.: Relative contribution of biogenic and anthropogenic sources to formic and acetic acids in the atmospheric boundary layer, J. Geophys. Res.-Atmos, 106, 74157426, 2001.

Greaves, T. L. and Drummond, C. J.: Protic ionic liquids: Properties and applications, Chem. Rev., 108, 206-237, 2008. 
Greaves, T. L., Weerawardena, A., Fong, C., Krodkiewska, I., and Drummond, C. J.: Protic ionic liquids: Solvents with tunable phase behavior and physicochemical properties, J. Phys. Chem. B, 110, 22479-22487, 2006.

Grönberg, L., Lövkvist, P., and Jönsson, J. A.: Measurement of aliphatic-amines in ambient air and rainwater, Chemosphere, 24, 1533-1540, 1992.

Hall, H. K.: Correlation of the base strengths of amines, J. Am. Chem. Soc., 79, 5441-5444 1957.

Hilal, S. H., Karickhoff, S. W., and Carreira, L. A.: A rigorous test for SPARC's chemical reactivity models: Estimation of more than 4300 ionization pK(a)s, Quant. Struct.-Act. Rel., 14, 348$355,1995$.

Hyvärinen, A. P., Lihavainen, H., Hautio, K., Raatikainen, T., Viisanen, Y., and Laaksonen, A.: Surface tensions and densities of sulfuric acid plus dimethylamine plus water solutions, J. Chem. Eng. Data, 49, 917-922, 2004.

Jaeschke, W., Dierssen, J. P., Gunther, A., and Schumann, M.: Phase partitioning of ammonia and ammonium in a multiphase system studied using a new vertical wet denuder technique, Atmos. Environ., 32, 365-371, 1998.

Jang, M. S. and Kamens, R. M.: Atmospheric secondary aerosol formation by heterogeneous reactions of aldehydes in the presence of a sulfuric acid aerosol catalyst, Environ. Sci. Technol., 35, 4758-4766, 2001.

Kerminen, V. M., Lihavainen, H., Komppula, M., Viisanen, Y., and Kulmala, M.: Direct observational evidence linking atmospheric aerosol formation and cloud droplet activation, Geophys. Res. Lett., 32, L14803, doi:10.1029/2005g1023130, 2005.

Kulmala, M., Vehkamäki, H., Petäjä, T., Dal Maso, M., Lauri, A., Kerminen, V. M., Birmili, W., and McMurry, P. H.: Formation and growth rates of ultrafine atmospheric particles: A review of observations, J. Aerosol Sci., 35, 143-176, 2004.

Laaksonen, A., Hamed, A., Joutsensaari, J., Hiltunen, L., Cavalli, F., Junkermann, W., Asmi, A., Fuzzi, S., and Facchini, M. C.: Cloud condensation nucleus production from nucleation events at a highly polluted region, Geophys. Res. Lett., 32, L06812, doi:10.1029/2004gl022092, 2005.

Li, Z. B. and Lu, B. C. Y.: Surface tension of aqueous electrolyte solutions at high concentrations - representation and prediction, Chem. Eng. Sci., 56, 2879-2888, 2001.

Lide, D. R. (Ed.): CRC Handbook of chemistry and physics, Taylor and Francis Group, Boca Raton, FL, USA, 88th Edition, 2008.

Linstrom, P. J. and Mallard, W. G. (Eds.): NIST Chemistry WebBook, NIST Standard Reference Database Number 69, National Institute of Standards and Technology, Gaithersburg, MD, USA, http://webbook.nist.gov, 2005.

Mäkelä, J. M., Yli-Koivisto, S., Hiltunen, V., Seidl, W., Swietlicki, E., Teinilä, K., Sillanpää, M., Koponen, I. K., Paatero, J., Rosman, K., and Hämeri, K.: Chemical composition of aerosol during particle formation events in boreal forest, Tellus B, 53, 380393, 2001.

Metzger, S., Mihalopoulos, N., and Lelieveld, J.: Importance of mineral cations and organics in gas-aerosol partitioning of reactive nitrogen compounds: Case study based on Minos results, Atmos. Chem. Phys., 6, 2549-2567, 2006, http://www.atmos-chem-phys.net/6/2549/2006/.

Metzger, S. and Lelieveld, J.: Reformulating atmospheric aerosol thermodynamics and hygroscopic growth into fog, haze and clouds, Atmos. Chem. Phys., 7, 3163-3193, 2007, http://www.atmos-chem-phys.net/7/3163/2007/.

Mircea, M., Facchini, M. C., Decesari, S., Cavalli, F., Emblico, L., Fuzzi, S., Vestin, A., Rissler, J., Swietlicki, E., Frank, G., Andreae, M. O., Maenhaut, W., Rudich, Y., and Artaxo, P.: Importance of the organic aerosol fraction for modeling aerosol hygroscopic growth and activation: A case study in the Amazon Basin, Atmos. Chem. Phys., 5, 3111-3126, 2005, http://www.atmos-chem-phys.net/5/3111/2005/.

Mmereki, B. T., Hicks, J. M., and Donaldson, D. J.: Adsorption of atmospheric gases at the air-water interface. 3: Methylamines, J. Phys. Chem. A, 104, 10789-10793, 2000.

Moffet, R. C., de Foy, B., Molina, L. T., Molina, M. J., and Prather, K. A.: Measurement of ambient aerosols in northern Mexico City by single particle mass spectrometry, Atmos. Chem. Phys., 8, 4499-4516, 2008, http://www.atmos-chemphys.net/8/4499/2008/.

Murphy, S. M., Sorooshian, A., Kroll, J. H., Ng, N. L., Chhabra, P., Tong, C., Surratt, J. D., Knipping, E., Flagan, R. C., and Seinfeld, J. H.: Secondary aerosol formation from atmospheric reactions of aliphatic amines, Atmos. Chem. Phys., 7, 2313-2337, 2007, http://www.atmos-chem-phys.net/7/2313/2007/.

Novakov, T. and Penner, J. E.: Large contribution of organic aerosols to cloud-condensation-nuclei concentrations, Nature, 365, 823-826, 1993.

O’Dowd, C. D., Hameri, K., Mäkelä, J., Vakeva, M., Aalto, P., de Leeuw, G., Kunz, G. J., Becker, E., Hansson, H. C., Allen, A. G., Harrison, R. M., Berresheim, H., Geever, M., Jennings, S. G., and Kulmala, M.: Coastal new particle formation: Environmental conditions and aerosol physicochemical characteristics during nucleation bursts, J. Geophys. Res.-Atmos., 107, 8107, doi:10.1029/2000jd000206, 2002.

Pankow, J. F.: Gas/particle partitioning of neutral and ionizing compounds to single and multi-phase aerosol particles. 1. Unified modeling framework, Atmos. Environ., 37, 3323-3333, 2003.

Pankow, J. F. and Asher, W. E.: SIMPOL.1: A simple group contribution method for predicting vapor pressures and enthalpies of vaporization of multifunctional organic compounds, Atmos. Chem. Phys., 8, 2773-2796, 2008, http://www.atmos-chem-phys.net/8/2773/2008/.

Paul, S. and Chandra, A.: Liquid-vapor interfacial properties of water-ammonia mixtures: Dependence of ammonia concentration, J. Chem. Phys., 123, 174712, doi:10.1063/1.2107428, 2005.

Pinder, R. W., Adams, P. J., and Pandis, S. N.: Ammonia emission controls as a cost-effective strategy for reducing atmospheric particulate matter in the eastern United States, Environ. Sci. Technol., 41, 380-386, 2007.

Pitts, J. N., Grosjean, D., Vancauwenberghe, K., Schmid, J. P., and Fitz, D. R.: Photo-oxidation of aliphatic-amines under simulated atmospheric conditions - formation of nitrosamines, nitramines, amides, and photo-chemical oxidant, Environ. Sci. Technol., 12, 946-953, 1978.

Poling, B. E., Prausnitz, J. M., and O'Connell, J. P.: The properties of gases and liquids, 5th Edition, McGraw-Hill, New York, USA, 2001.

Raatikainen, T., Laaksonen, A., Hyvärinen, A. P., Vanhanen, J., Hautio, K., Lihavainen, H., Viisanen, Y., and Napari, I.: Surface tensions of multicomponent aqueous electrolyte solutions: Predictive models based on binary limits, J. Phys. Chem. C, 112, 
10428-10434, 2008.

Rabaud, N. E., Ebeler, S. E., Ashbaugh, L. L., and Flocchini, R. G.: Characterization and quantification of odorous and non-odorous volatile organic compounds near a commercial dairy in California, Atmos. Environ., 37, 933-940, 2003.

Rampfl, M., Mair, S., Mayer, F., Sedlbauer, K., Breuer, K., and Niessner, R.: Determination of primary, secondary, and tertiary amines in air by direct or diffusion sampling followed by determination with liquid chromatography and tandem mass spectrometry, Environ. Sci. Technol., 42, 5217-5222, 2008.

Samson, E., Lemaire, G., Marchand, J., and Beaudoin, J. J.: Modeling chemical activity effects in strong ionic solutions, Comp. Mater. Sci., 15, 285-294, 1999.

Seinfeld, J. H. and Pandis, S. N.: Atmospheric chemistry and physics: From air pollution to climate change, John Wiley \& Sons, Inc., New York, USA, 523-538, 1998.

Silva, P. J. and Prather, K. A.: Interpretation of mass spectra from organic compounds in aerosol time-of-flight mass spectrometry, Anal. Chem., 72, 3553-3562, 2000.

Smith, J. N., Dunn, M. J., VanReken, T. M., Iida, K., Stolzenburg, M. R., McMurry, P. H., and Huey, L. G.: Chemical composition of atmospheric nanoparticles formed from nucleation in Tecamac, Mexico: Evidence for an important role for organic species in nanoparticle growth, Geophys. Res. Lett., 35, L04808, doi:10.1029/2007g1032523, 2008.

Sotiropoulou, R. E. P., Tagaris, E., Pilinis, C., Anttila, T., and Kulmala, M.: Modeling new particle formation during air pollution episodes: Impacts on aerosol and cloud condensation nuclei, Aerosol Sci. Tech., 40, 557-572, 2006.

Spracklen, D. V., Carslaw, K. S., Kulmala, M., Kerminen, V. M., Sihto, S. L., Riipinen, I., Merikanto, J., Mann, G. W., Chipperfield, M. P., Wiedensohler, A., Birmili, W., and Lihavainen, H.: Contribution of particle formation to global cloud condensation nuclei concentrations, Geophys. Res. Lett., 35, L06808, doi:10.1029/2007g1033038, 2008.

Sprow, F. B. and Prausnitz, J. M.: Surface tensions of simple liquids mixtures, T. Faraday Soc., 62, 1105-1111, 1966.

Stolzenburg, M. R., McMurry, P. H., Sakurai, H., Smith, J. N., Mauldin, R. L., Eisele, F. L., and Clement, C. F.: Growth rates of freshly nucleated atmospheric particles in Atlanta, J. Geophys. Res.-Atmos., 110, D22s05, doi:10.1029/2005jd005935, 2005.

Suarez, J. T., Torres-Marchal, C., and Rasmussen, P.: Prediction of surface tension of nonelectrolyte solutions, Chem. Eng. Sci., 44, $782-785,1989$.
Tobias, H. J. and Ziemann, P. J.: Kinetics of the gas-phase reactions of alcohols, aldehydes, carboxylic acids, and water with the 13 stabilized Criegee intermediate formed from ozonolysis of 1-tetradecene, J. Phys. Chem. A, 105, 6129-6135, 2001.

Trebs, I., Metzger, S., Meixner, F. X., Helas, G. N., Hoffer, A., Rudich, Y., Falkovich, A. H., Moura, M. A. L., da Silva, R. S., Artaxo, P., Slanina, J., and Andreae, M. O.: The $\mathrm{NH}_{4}^{+}-\mathrm{NO}_{3}^{-}$$\mathrm{Cl}^{-}-\mathrm{SO}_{4}^{2-}-\mathrm{H}_{2} \mathrm{O}$ aerosol system and its gas phase precursors at a pasture site in the Amazon Basin: How relevant are mineral cations and soluble organic acids?, J. Geophys. Res.-Atmos., 110, D07303, doi:10.1029/2004jd005478, 2005.

Tyn, M. T. and Calus, W.: Processing, 21 (4), 14, 1975.

Vesterinen, M., Lehtinen, K. E. J., Kulmala, M., and Laaksonen, A.: Effect of particle phase oligomer formation on aerosol growth, Atmos. Environ., 41, 1768-1776, 2007.

Weber, R. J., McMurry, P. H., Eisele, F. L., and Tanner, D. J.: Measurement of expected nucleation precursor species and 3-500-nm diameter particles at Mauna-Loa-Observatory, Hawaii, J. Atmos. Sci., 52, 2242-2257, 1995.

Weber, R. J., Marti, J. J., McMurry, P. H., Eisele, F. L., Tanner, D. J., and Jefferson, A.: Measurements of new particle formation and ultrafine particle growth rates at a clean continental site, J. Geophys. Res.-Atmos., 102, 4375-4385, 1997.

Weissenborn, P. K. and Pugh, R. J.: Surface tension of aqueous solutions of electrolytes: Relationship with ion hydration, oxygen solubility, and bubble coalescence, J. Colloid Interf. Sci., 184, 550-563, 1996.

Yoshizawa, M., Xu, W., and Angell, C. A.: Ionic liquids by proton transfer: Vapor pressure, conductivity, and the relevance of delta pK(a) from aqueous solutions, J. Am. Chem. Soc., 125, 1541115419, 2003.

Zhang, K. M. and Wexler, A. S.: A hypothesis for growth of fresh atmospheric nuclei, J. Geophys. Res.-Atmos., 107, 4577, doi:10.1029/2002jd002180, 2002.

Zhang, R. Y., Suh, I., Zhao, J., Zhang, D., Fortner, E. C., Tie, X. X., Molina, L. T., and Molina, M. J.: Atmospheric new particle formation enhanced by organic acids, Science, 304, 1487-1490, 2004.

Zhang, S. J., Sun, N., He, X. Z., Lu, X. M., and Zhang, X. P.: Physical properties of ionic liquids: Database and evaluation, J. Phys. Chem. Ref. Data, 35, 1475-1517, 2006. 